\title{
El territorio a discusión. Procesos globales, neoliberalismo y política urbana
}

\section{The territory under discussion. Global processes, neoliberalism and urban policy}

\author{
Ramírez, Blanca Rebeca y Emilio Pradilla (comps.) (2013), \\ TEORÍAS Y POLITITCAS TERRITORIALES, UnIVERSIDAD AutÓNOMA \\ Metropolitana Xochimilco, Colección Antologías, México, \\ 38I PP., ISBN 978-607-28-0060-I
}

El libro Teorias y politicas territoriales es una compilación de artículos y capítulos de libros elaborados en la última década, varios de ellos se publicaron previamente en revistas nacionales de reconocido prestigio como Secuencia del Instituto de Investigaciones "Dr. José María Luis Mora” y Ciudades de la Red Nacional de Investigación Urbana. También se recopilaron en este texto trabajos provenientes de revistas extranjeras, como es el caso de dos artículos publicados en la Revista Brasileira de Estudios Urbano e Regionais y en Cadernos Metrópole.

Sobre los autores de los trabajos publicados destacan los académicos ampliamente reconocidos en el ámbito de los estudios sobre el territorio, la región y la ciudad, es el caso de Daniel Hiernaux, Rafael López Rangel, Roberto Eibenschutz Hartman y Alicia Lindón; además de los propios compiladores de la obra: Blanca Ramírez y Emilio Pradilla.

El objetivo de la recopilación es poner a disposición de profesores y alumnos de la licenciatura en Planeación Territorial (perteneciente a la División de Ciencias y Artes para el Diseño de la Universidad Autónoma Metropolitana-Xochimilco), material de discusión y análisis sobre la materia. Reconociéndose claramente que este tipo de obras de compilación son necesarias para una enseñanza adecuada y eficaz en el sistema educativo a nivel superior.

De acuerdo con Ramírez y Pradilla, los 11 trabajos que se publicaron en la antología tienen en común que son relevantes para la formación académica de los estudiantes, quienes en muchos casos quizá se integren a la administración gubernamental o económica en el país. Cabe mencionar que algunos de los artículos editados en la obra presentan un enfoque predominantemente teórico, abordando a nivel conceptual la cuestión regional y territorial, la complejidad y la ciudad, la globalización y el neoliberalismo; así como el enfoque de la ecología social. Un segundo conjunto de trabajos 
tiene el objetivo de mostrar la discusión alrededor de las políticas públicas y su enfoque territorial, para el caso de la ciudad de México, el ámbito mexicano y, en general, para América Latina.

Blanca Ramírez al igual que Emilio Pradilla tienen una trayectoria académica de larga envergadura, la primera es geógrafa de profesión, con estudios en planeación regional y urbanismo, posee una amplia carrera en docencia de la geografía y cuestiones regionales y territoriales a nivel licenciatura y posgrado. Desde finales de los años ochenta hasta la actualidad, sus artículos, capítulos de libro y obras como compiladora o autora dan cuenta de la preocupación por los temas de la planeación y la discusión conceptual y aplicada del territorio, refiriéndolo al contexto de las políticas neoliberales en boga.

Por su parte, Emilio Pradilla es arquitecto de licenciatura con posgrados en urbanismo, y una amplia experiencia en sus primeros años profesionales en la práctica de planeación gubernamental en su natal Colombia. Hacia la segunda mitad de los setenta es clara ya su tendencia a la investigación y la docencia en México, desarrollando su carrera en la Universidad Nacional Autónoma de México (UnAM) y en la UAM. Asimismo, se perfilan en sus trabajos el análisis y la discusión de la planeación regional, la vivienda y el proceso urbano en México y, particularmente, en el Distrito Federal, ampliando incluso su reflexión al caso de América Latina en los temas citados.

Por supuesto que esta síntesis no hace justicia a la dilatada trayectoria de ambos investigadores adscritos a la UAM Xochimilco, pero si es pertinente para entender quiénes son los académicos que plantearon la propuesta de la compilación en temas que son de su entero conocimiento y especialización. Los trabajos que se recopilan en el libro presentan un orden, que como ya se ha dicho más arriba, recorre el espectro teórico y reflexivo de la planeación territorial y urbana, en el marco del neoliberalismo y la globalización; a un conjunto de documentos que abordan la práctica de las políticas de corte regional o territorial y su aplicación concreta.

El primer artículo que inegra esta obra, titulado "El concepto de espacio y el análisis regional" de Daniel Hiernaux y Alicia Lindón, trata sobre definiciones conceptuales del espacio, éste se ha convertido en un texto multicitado en México por los investigadores del tema regional y territorial. La claridad en la exposición de cuestiones teóricas sobre el espacio geográfico y la evolución de la categoría región; son aspectos que contribuyen a definir puntos de partida para cualquier interesado en la discusión de tales temas, como lo seńalan explícitamente Ramírez y Pradilla.

En el segundo texto de esta antología, "Impensar la ciudad o en busca del pensamiento complejo” de Rafael López Rangel centra su análisis 
propiamente en la ciudad haciendo un recorrido por el estado del arte de los estudios contemporáneos sobre el ámbito urbano en México. Para los compiladores, el texto da cuenta de dos cuestiones que no se deben perder de vista: la complejidad del estudio de las ciudades y las diversas visiones y posibilidades para su examen.

"Procesos territoriales, escalas y utopías" es el título del texto de Blanca Ramírez, el cual tiene como aspecto central discutir las implicaciones territoriales contemporáneas en relación al contexto neoliberal y globalizante, haciendo hincapié en que las fallas sobre la acción en el territorio son producto en buena medida por la falta de relaciones adecuadas y consensadas entre los agentes humanos e institucionales que están presentes en dicho espacio y actúan sobre él.

El cuarto trabajo que integra este texto es "Globalización y territorio: una síntesis de sus contenidos y ejes de discusión” de Ricardo Pino, quien revisa la relación existente entre la globalización y el territorio enfocándose en investigaciones que la discuten y caracterizan. La finalidad del análisis fue estudiar cómo conceptualmente se define dicha relación, además de mostrar la forma que en México ha tenido un impacto territorial la globalización.

Abordando un nivel espacial más amplio, es decir, América Latina, Emilio Pradilla expone información cuantitativa sobre el impacto del neoliberalismo en los procesos urbanos y económicos; dando cuenta de un aumento en la pobreza, la informalidad en el sector terciario, la pérdida de industrias y una política urbana que no corresponde a las necesidades de los países latinoamericanos, de estos temas trata su artículo "Mundialización neolibreral, cambios urbanos y políticas estatales".

Un sexto artículo que integra esta antología se titula "Ecología social, una agenda mínima para su discusión” de Ricardo Pino, en su texto aborda un aspecto no de menor importancia en el contexto de la globalización y su impacto territorial: la crisis ambiental. Siendo ésta un problema complejo y de múltiples aristas, para Pino la ecología social abarca el espectro no sólo de lo ambiental como tal, sino involucra también a la política como un factor que puede coadyuvar al planteamiento de soluciones.

El examen de la política regional mexicana se plantea en el artículo: "Aspectos fundamentales para la comprensión de las políticas regionales 1976-1992” de Blanca Ramírez, este texto estudia la forma en la que el Estado incursionó territorialmente en el país en ese periodo, cuando el proyecto neoliberal se perfiló de manera más nítida.

Por su parte, Ángel Mercado, en su artículo "Reservas territoriales para usos urbanos en el Distrito Federal”, advierte que, en dichos espacios a mediados de los años noventa del siglo pasado, las tareas de planeación 
fueron importantes para establecer escenarios de crecimiento urbano; sin embargo, el autor demuestra que muchos planes carecían de dicha previsión, e incluso, argumenta que el crecimiento y desarrollo de la población es la que orienta y estimula la apropiación del territorio y que no es sólo el gobierno quien organiza dicha actividad.

"Una estrategia para el futuro de la metropoli" es el título del texto de Roberto Eibenschutz, y cuya elaboración data de mediados de la década de los noventa del siglo pasado, en éste expone una realidad que la Ciudad de México vivía y vive actualmente; ya que a la par del crecimiento económico, social y urbano para muchos habitantes de la capital, se hacían sentir los efectos contrarios para otros sectores menos favorecidos. De hecho, el documento delinea también un proyecto de ciudad, estipulando los lineamientos territoriales y plazos necesarios para su concreción.

Felipe Moreno en su texto, "Relaciones entre la estructuración terciaria de la ciudad de México y los movimientos sociales urbanos 1980-2010", plantea que en ese contexto, no sólo se trató de cómo dicho sector económico modificó vialidades y espacios públicos, y los efectos negativos a nivel social que trajo aparejado este proceso para diversos grupos de la población de la capital del país; sino también lo que originó en términos de movimientos populares que se opusieron justamente a los efectos adversos. Aquí nuevamente se pone de manifiesto el alcance de las políticas neoliberales en el sector económico y cómo esto trajo por igual la aparición de cambios en la estructura social urbana.

Finalmente, Emilio Pradilla en su artículo, "Teorías y políticas urbanas: libre mercado mundial o construcción regional", hace un ejercicio crítico de las políticas neoliberales emprendidas en América Latina, discutiendo su viabilidad dados los resultados negativos que se presentan en los diversos países. Cuestiona la pretendida homogeneidad de las soluciones neoliberales que ignoran las particularidades que posee el territorio latinoamericano. Precisamente para el autor es necesario emprender una construcción regional con las realidades y necesidades de la población latinoamericana y, derivado de ello, definir las políticas estatales necesarias para resolver los problemas sociales, económicos y políticos.

La ilación de los textos que reúne la compilación tiene una estructura que va de lo teórico y conceptual, a la caracterización y contrastación empírica de políticas estatales y neoliberales; ya sea a una escala latinoamericana, o para el caso de México y, particularmente, del Distrito Federal. Asimismo, es importante recalcar que varios de los trabajos reunidos en la recopilación, si bien, sobre todo los elaborados por Pradilla, discuten y advierten que no se pueden aplicar en México y América Latina modelos teóricos y de planeación de origen neoliberal sin hacer una rigurosa crítica de su viabilidad. 
Una antología como la realizada por Ramírez y Pradilla tiene por supuesto alcances mayores en términos de su posible difusión. Esto es así porque en muchas instituciones y centros universitarios seguramente se harán uso de los materiales reunidos, dada su calidad académica y utilidad para la enseñanza y discusión de temas relativos al territorio, la globalización y la ciudad. Reunir documentos, de alguna manera dispersos, dada su publicación en diversas revistas y libros, con la finalidad de ponerlos a la disposición de profesores y alumnos en una obra unitaria, es un acierto que los mismos autores reconocen como una tarea a seguir desarrollando en el futuro con otros conjuntos de trabajos relativos a la planeación territorial.

En este sentido, quizá una ruta que debiera seguirse es precisamente la reunión de trabajos de los mismos autores de la compilación, con la finalidad de difundir de forma integra un conjunto de resultados de investigación que sirvan de igual forma a las generaciones futuras interesadas en los temas del territorio, la planeación, las políticas urbanas y el neoliberalismo.

Recibida: 30 de junio de 2014. Aceptada: 4 de julio de 2014.

Carlos Bustamante-López Centro de Investigaciones Interdisciplinarias sobre Desarrollo Regional (CIISDER) Universidad Autónoma de Tlaxcala Correo electrónico: bustamante25@hotmail.com

Carlos Bustamante-López. Mexicano. Doctor en historia por la Universidad Autónoma Metropolitana unidad Iztapalapa. Adscrito al Centro de Investigaciones Interdisciplinarias sobre Desarrollo Regional (CIISDER)Universidad Autónoma de Tlaxcala. Entre sus líneas de investigación destacan: historia política y regional y alternancia política, Miembro del Sistema Nacional de Investigadores de Conacyt, nivel I. Fue coordinador de las siguientes publicaciones: Simetrías y asimetrías en una sociedad compleja. Aproximaciones teórico-metodológicas, CIISDER-Universidad Autónoma de Tlaxcala, Tlaxcala, 178 pp. (2012); Teoría metodología del análisis sociopolítico, CIISDER-Universidad Autónoma de Tlaxcala, Tlaxcala, 202 pp. (2013); Ciudadanía fragmentada. La sociabilidad politica entre la resistencia y la desafección, CIISDER-Universidad Autónoma de Tlaxcala, Tlaxcala, 245 pp. (2014). 